\title{
Establishing the effect of loop length on dimensional stability of single jersey knitted fabric made from cotton/lycra core spun yarn
}

\author{
C. Prakash ${ }^{1}$ and K. Thangamani ${ }^{2}$ \\ ${ }^{1}$ Dept. of Fashion Technology, Sona College of Technology, Salem - 636 005, TN, India \\ ${ }^{2}$ Dept. of Textile Technology, Kumaraguru College of Technology, Coimbatore - 641 006, TN, India \\ dearcprakash@rediffmail.com
}

\begin{abstract}
Munden and earlier workers established that in plain knitted fabrics the fabric dimensional parameters namely Kc, Kw and Ks are constant at dry and wet relaxed state for wool, cotton, orlon and nylon yarns. But in the present study of cotton/lycra core spun yarn single jersey derivative knitted fabrics the values for Kc, Kw and Ks varies with loop length. The ratio of Kc/Kw also varies with loop length. In this paper, Single jersey fabric is produced from Polyester/lycra aircovered yarn with different loop lengths. The study covers about the testing of dimensional properties of the single jersey knitted fabric. After the fabric production, the fabric was dry relaxed. Wales per inch, courses per inch, fabric width, loop length and fabric thickness are all measured. Then the fabric was wet relaxed and tested for the above parameters. Then the samples were heat set at various stretch levels at $180^{\circ} \mathrm{C}$. From the study, it was found that the dimension of fabric shows considerable change during wet relaxation. The fabric shows very good appearance when heat set at all stretch levels at $180^{\circ} \mathrm{C}$ in course direction. The fabric with a loop length of $2.5 \mathrm{~mm}$ was found to have better appearance when compared to the fabrics of other loop lengths. In particular $10 \%$ stretch level shows a better appearance for $2.5 \mathrm{~mm}$ loop length.
\end{abstract}

Keywords: Dimensional stability, dry relaxation, wet relaxation, cotton/lycra core spun yarn, loop length, single jersey knitted fabric.

\section{Introduction}

Dimensional stability of weft-knitted fabrics is a serious problem in view of fabric quality control (Keshkari 2002; Punj. 2000). There are reports available on the geometry and dimensional properties of plain knitted fabrics (Mokhopadhyay et al., 2003). Doyle and Hurd (1953), found that the stitch density of plain knitted fabrics in the dry relaxed state is dependent only on the loop length, and independent of other yarn and knitting variables.

Munden (1959) has shown that the natural shape of loop is determined by minimum energy conditions, and that assumes only loop similarity and derives geometrically the well-known relations $\left(\mathrm{k}_{\mathrm{c}}=\mathrm{c} \times l, \mathrm{k}_{\mathrm{w}}=\mathrm{w} \mathrm{x}\right.$ $l, \mathrm{k}_{\mathrm{s}}=\mathrm{k}_{\mathrm{c}} \times \mathrm{k}_{\mathrm{w}}$ and $\mathrm{k}_{\mathrm{r}}=\mathrm{k}_{\mathrm{c}} / \mathrm{k}_{\mathrm{w}}$ where $\mathrm{c}$ and $\mathrm{w}$ are the courses/unit length and wales/unit length and $l$ is the loop length (length of yarn knitted in one loop), $s$ the stitch density or No. of loops per unit area and Kc, Kw, and Ks are constants such that $\mathrm{k}_{\mathrm{c}} \times \mathrm{k}_{\mathrm{w}}=\mathrm{k}_{\mathrm{s}}$ and are called as fabric dimensional parameters). Munden found out the values for $\mathrm{Kc}, \mathrm{Kw}$ and $\mathrm{Ks}$ for the worsted plain knit fabrics from experimental measurements.

\begin{tabular}{|c|c|c|}
\hline Values for K & Dry relaxed & Wet relaxed \\
\hline $\mathrm{Kc}$ & 5.0 & 5.3 \\
$\mathrm{Kw}$ & 3.8 & 4.1 \\
\hline $\mathrm{Kc} / \mathrm{Kw}$ & \multicolumn{2}{|c|}{1.3} \\
\hline
\end{tabular}

Nuting and Leaf (1964) has proposed a generalized geometry of weft-knitted fabrics which introduced a term involving the yam diameter. Knapton (1979) has shown that dimensional stability in cotton plain-jersey fabrics can be attained by either mechanical relaxation techniques or chemical treatments, and that k-values are not entirely independent of the fabric tightness $\mathrm{K}(=\sqrt{\mathrm{T}} / l$, where $\mathrm{T}$ is the linear density in tex) and some yarn variables, and that the ratio $t / l$ is in proportion to the fabric tightness for the completely relaxed cotton plain fabrics. Postle and Munden (1967) has shown that the value of ratio $\mathrm{t} /$ becomes 0.147 for plain-knitted fabrics. In this paper, studies have been done on the dimensional properties of knitted fabrics produced from air-covered elastomeric yarn. Here, Lycra polyester air-covered yarn is knitted into single jersey fabric and their properties have been tested on this knitted structure.

\section{Experimental}

The experimental samples were knitted on a 24 Gauge 24" dia high speed circular knitting machine equipped with positive feeders. Cotton/ Lycra core spun yarn of 30 s count was used to produce the fabrics. The denier of lycra filament is 40 . Samples were produced with 3 levels of loop length on single jersey derivatives. The samples were subjected to the following dry relaxation and wet relaxation. For dry relaxation, samples were left lying on a smooth flat surface in standard atmosphere for 3 days. Then the samples were bleached using hydrogen peroxide and dried in accordance with
Research article

CIndian Society for Education and Environment (iSee)
"Dimensional stability of Knitted yarn" http://www.indjst.org
Prakash \& Thangamani Indian J.Sci.Technol. 

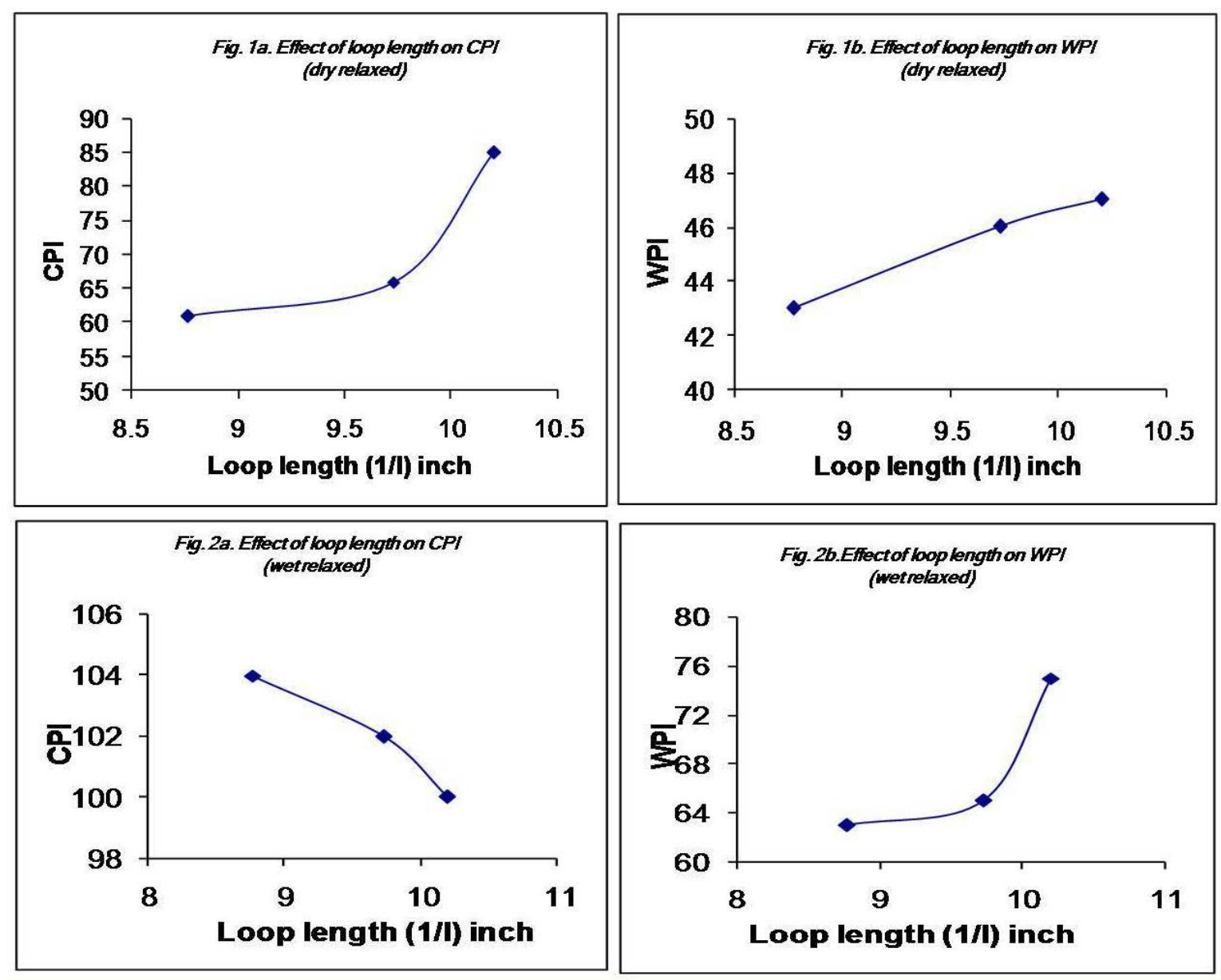

Table 1 Effect of loop length on fabric parameters at

\begin{tabular}{|l|l|l|l|l|l|l|l|}
\hline $\begin{array}{l}\text { Loop length } \\
\text { mm (inch) }\end{array}$ & CPI & WPI & $\mathrm{K}_{\mathrm{c}}$ & $\mathrm{K}_{\mathrm{w}}$ & $\mathrm{N}$ & $\mathrm{K}_{\mathrm{s}}$ & $\mathrm{K}_{\mathrm{c}} / \mathrm{K}_{\mathrm{w}}$ \\
\hline $2.5(0.098)$ & 85 & 47 & 8.33 & 4.61 & 3995 & 38.37 & 1.81 \\
$2.7(0.106)$ & 66 & 46 & 6.99 & 4.88 & 3036 & 34.11 & 1.43 \\
$2.9(0.114)$ & 61 & 43 & 6.95 & 4.90 & 2623 & 34.05 & 1.41 \\
\hline
\end{tabular}

Table 3. Effect of stretching \& heat Setting on CPI \& WPI $(2.5 \mathrm{~mm}$ loop length)

\begin{tabular}{|c|c|c|c|}
\hline $\begin{array}{c}\text { Loop length } \\
\text { mm (inch) }\end{array}$ & $\begin{array}{c}\text { Stretch } \\
\text { level (\%) }\end{array}$ & $\begin{array}{c}\text { Course } \\
\text { /inch }\end{array}$ & $\begin{array}{c}\text { Wales } \\
\text { /inch }\end{array}$ \\
\hline & 10 & 110 & 58 \\
& 20 & 111 & 54 \\
$2.5(0.098)$ & 30 & 114 & 50 \\
& 50 & 117 & 46 \\
& 70 & 119 & 44 \\
& 90 & 123 & 36 \\
\hline
\end{tabular}

Table 2. Effect of loop length on fabric parameters at wet relaxed state

\begin{tabular}{|l|l|l|l|l|l|l|l|}
\hline $\begin{array}{l}\text { Loop length } \\
\text { mm (inch) }\end{array}$ & CPI & WPI & $\mathrm{K}_{\mathrm{c}}$ & $\mathrm{K}_{\mathrm{w}}$ & $\mathrm{N}$ & $\mathrm{K}_{\mathrm{s}}$ & $\mathrm{K}_{\mathrm{c}} / \mathrm{K}_{\mathrm{w}}$ \\
\hline $2.5(0.098)$ & 100 & 75 & 9.8 & 7.35 & 7500 & 72.03 & 1.33 \\
$2.7(0.106)$ & 102 & 65 & 10.8 & 6.89 & 6630 & 74.41 & 1.57 \\
$2.9(0.114)$ & 104 & 63 & 11.86 & 7.18 & 6552 & 85.15 & 1.65 \\
\hline
\end{tabular}

Table 4. Effect of stretching \& heat Setting on CPI \& WPI (2.7 mm loop length)

\begin{tabular}{|c|c|c|c|}
\hline $\begin{array}{c}\text { Loop length } \\
\text { mm (inch) }\end{array}$ & $\begin{array}{c}\text { Stretch } \\
\text { level (\%) }\end{array}$ & $\begin{array}{c}\text { Course } \\
\text { /inch }\end{array}$ & $\begin{array}{c}\text { Wales } \\
\text { linch }\end{array}$ \\
\hline & 10 & 104 & 56 \\
& 20 & 106 & 54 \\
& 30 & 109 & 52 \\
& 50 & 110 & 46 \\
& 70 & 115 & 42 \\
& 90 & 120 & 40 \\
\hline
\end{tabular}


current manufacturing practices. Measurement were Conclusions taken on samples in wet relaxation state as reported by

From the study, it was found that the dimension of Bayazit Marmarali (2003).

Loop length $l$ : The length of ten

Table 5. Effect of stretching \& heat setting on $\mathrm{CPI} \& \mathrm{WPI}$

unrowed courses each of which containing fifty wales was measured and the average was calculated. This average value was divided by fifty to find the length of one loop (Choi \& Ashdown, 2000).

Course and wales spacing: The number of courses and wales in a 1" length fabric were determined at ten different places on every sample with a magnifying glass and the average values were calculated. (Mikučionienè, 2004).

Results and discussions

The test results for Dry-Relaxed state are given in Table 1 and for Wet-Relaxed state in Table 2. From the Table 1, it is been found that the values of CPI, WPI, $\mathrm{Kc}, \mathrm{Kw}, \mathrm{N}, \mathrm{Ks}$ and $\mathrm{Kc} / \mathrm{Kw}$ varies with respect to loop length and also found decreased in the CPI, WPI, $\mathrm{Kc}, \mathrm{N}, \mathrm{Ks}$ and $\mathrm{Kc} / \mathrm{Kw}$ values and an increased $\mathrm{Kw}$ value during Dry Relaxation process. Results are shown in Fig. 1a \& 1b. From the Table 2, it is been found that the values of $\mathrm{CPI}, \mathrm{WPI}, \mathrm{Kc}, \mathrm{Kw}, \mathrm{N}$, Ks and $\mathrm{Kc} / \mathrm{Kw}$ varies with respect to loop length. Also there has been an increase in the initial $\mathrm{CPI}, \mathrm{Kc}, \mathrm{Ks}$ and $\mathrm{Kc} / \mathrm{Kw}$ values, while a decrease in WPI \& N value and a subsequent decrease and increase in $\mathrm{Kw}$ value during wet relaxation process. Results are shown in Fig. 2a \& 2b. From the Tables 3-5, it is been found that CPI and WPI value varies with respect to stretch level at constant loop length and also a decrease in the wales per inch and increase in courses per inch.

From the Table 6, it is found that Courses per inch values varies with respect to loop length and also a considerable increase in the Course per inch after hot washing. Wales per inch values varies with respect to loop length and also decreases after hot washing (Table 7). Loop length values vary before and after wet relaxation and found a minimal change in the loop length after hot washing (Table 8). From the Table 9, it is been found that width of fabric values varies with respect to loop length and also a decrease in the width of fabric after hot washing. From the Table 10 and Fig. 3, it is been found that thickness of fabric values varies with respect to loop length and also an increase in the thickness of fabric after hot washing. 561-578. fabric shows considerable change during wet relaxation. The $\mathrm{CPI}$ increases from $17.65 \%$ to $70.49 \%$ and an average percentage change in $\mathrm{CPI}$ is $47.56 \%$ after Wet-Relaxation. The WPI decreases from $59.57 \%$ to $31.75 \%$ and an average percentage change in WPI is $44.2 \%$ after WetRelaxation. The fabric shows better appearance when heat set at all stretch levels at $180^{\circ} \mathrm{C}$ in course direction. A fabric with a loop length of $2.5 \mathrm{~mm}$ gives better appearance when compared to the fabrics of other loop lengths. In particular $10 \%$ stretch level shows impressive appearance for $2.5 \mathrm{~mm}$ loop length.

\section{References}

1. Bayazit Marmarali A (2003) Dimensional and physical properties of cotton/spandex single jersey fabrics, Text. Res. J. 73 (1), 11-14.

2. Choi MS and Ashdown SP (2000) Effect of changes in knit structure and density on the mechanical and hand properties of weft-knitted fabrics for outwear, Text. Res. J. 70 (12), 1033-1045.

3. Doyle PJ and Hurd JCH (1953) Fundamental aspects of the design of knitted fabrics. J. Text. Inst. 44 (8),

4. Keshkari KR (2002) Effect of yarn feed length on cotton weft knitted Fabrics, The Indian Tex. J., 112(6), 131-136.

5. Knapton JJF (1979) The wet-relaxed dimensions of plain-knitted fabrics. J. Text. Inst. 70 (9), 410.

6. Mikučioniene (2004) The dimensional change of used pure and compound cotton knitwear. Material Sci. 10 (1), 93-96.

7. Mokhopadhyay A, Sharma IC and Mohanty A (2003) Impact of lycra filament on extension and recovery characteristics of cotton knitted fabric, Indian J. Fibre. Textil. Res. 28, 423-430.

8. Munden DL (1959) The geometry and dimensional properties of plain-knit fabrics. J. Text. Inst. 50 (7), 448-471.

9. Nuting TS and Leaf GAV (1964) A generalized geometry of weft knitted fabrics. J. Text. Inst. 55, 45-53.

10. Postle R and Munden DL (1967) Analysis of the dry relaxed knitted loop configuration. J. Text. Inst. 58 (8), 329-365.

11. Punj SK (2000) Plain knitted properties. Text.Asia. 31, 33-38.

Table 9. Effect of loop length on width of fabric

\begin{tabular}{|c|c|c|c|}
\hline $\begin{array}{c}\text { Loop length } \\
\text { mm (inch) }\end{array}$ & $\begin{array}{c}\text { Width of } \\
\text { grey fabric } \\
(\mathrm{cm})\end{array}$ & $\begin{array}{c}\text { Width of fabric } \\
\text { after hot wash } \\
(\mathrm{cm})\end{array}$ & $\begin{array}{c}\text { \% of shrinkage } \\
\text { in the fabric } \\
\text { after hot wash }\end{array}$ \\
\hline $2.5(0.098)$ & 72.0 & 54.2 & 25.72 \\
$2.7(0.106)$ & 71.5 & 55.5 & 22.38 \\
$2.9(0.114)$ & 70.5 & 56.0 & 20.57 \\
\hline
\end{tabular}

